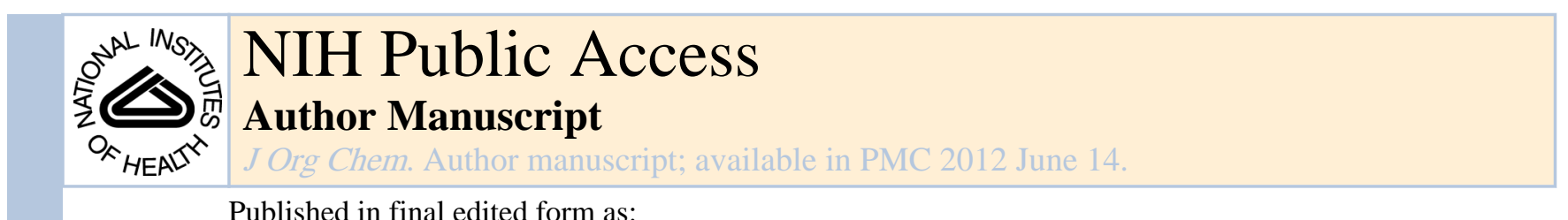

J Org Chem. 2007 September 14; 72(19): 7343-7351. doi:10.1021/jo071210y.

\title{
Callophycoic Acids and Callophycols from the Fijian Red Alga Callophycus serratus
}

\author{
Amy L. Lane ${ }^{\dagger}$, Elizabeth P. Stout ${ }^{\dagger}$, Mark E. Hay $^{\ddagger}$, Anne C. Prusak ${ }^{\ddagger}$, Kenneth Hardcastle , \\ Craig R. Fairchild ${ }^{\perp}$, Scott G. Franzblau" , Karine Le Roch\# ${ }^{\#}$, Jacques Prudhomme ${ }^{\#}$, William \\ Aalbersberg ${ }^{\&}$, and Julia Kubanek ${ }^{*}, \dagger, \neq$ \\ School of Chemistry and Biochemistry and School of Biology, Georgia Institute of Technology, \\ Atlanta, Georgia 30332, Department of Chemistry, Emory University, Atlanta, Georgia 30322, \\ Bristol-Myers Squibb Pharmaceutical Research Institute, Princeton, New Jersey 08543, Institute \\ for Tuberculosis Research, College of Pharmacy, University of Illinois at Chicago, Chicago, \\ Illinois 60612, Department of Cell Biology and Neuroscience, University of California Riverside, \\ Riverside, California 92521, and Institute of Applied Sciences, University of the South Pacific, \\ Suva, Fiji
}

\begin{abstract}

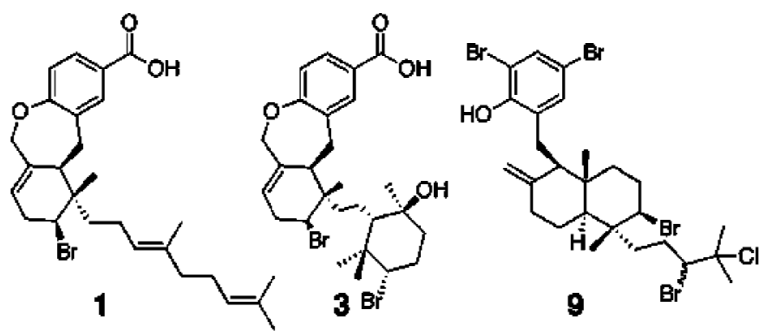

Callophycoic acids A-H (1-8) and callophycols A and B (9 and 10) were isolated from extracts of the Fijian red alga Callophycus serratus, and identified by NMR, X-ray, and mass spectral analyses. These natural products represent four novel carbon skeletons, providing the first examples of diterpene-benzoic acids and diterpene-phenols in macroalgae. Compounds 1-10 exhibited antibacterial, antimalarial, and anticancer activity, although they are less bioactive than diterpene-benzoate macrolides previously isolated from this red alga.
\end{abstract}

\section{Introduction}

Red macroalgae are well-known producers of bioactive secondary metabolites, including isoprenoid and phenolic metabolites. ${ }^{1}$ However, the discovery of metabolites with novel carbon skeletons and mixed biosynthetic origin is uncommon. Recently, 10 novel bioactive diterpene-benzoate macrolides, representing two new carbon skeletons, were isolated from a

\footnotetext{
(C) 2007 American Chemical Society

julia.kubanek@biology.gatech.edu.

TSchool of Chemistry and Biochemistry, Georgia Institute of Technology.

\#School of Biology, Georgia Institute of Technology.

Emory University.

${ }^{\perp}$ Bristol-Myers Squibb Pharmaceutical Research Institute.

"University of Illinois at Chicago.

\#University of California Riverside.

$\&_{\text {University of the South Pacific. }}$
}

Supporting Information Available: COSY, HMBC, and NOE data, ${ }^{1} \mathrm{H}$ and ${ }^{13} \mathrm{C}$ NMR spectra for 1-10, and X-ray crystallographic data (tables and CIF files) for $\mathbf{1}$. This material is available free of charge via the Internet at http://pubs.acs.org. 
Fijian collection of Callophycus serratus, ${ }^{2,3}$ a member of the largely unstudied Solieriaceae family of red algae. To further characterize the secondary metabolism of $C$. serratus, a second Fijian population was analyzed. This exploration led to the isolation of eight novel bioactive diterpene-benzoic acids (1-8) and two novel halogenated diterpene-phenols (9 and 10), whose structure elucidation and biological activities are presented herein.

\section{Results and Discussion}

A toxicity assay based upon ingestion rates of the invertebrate rotifer Brachionus calyciflorus was used to guide the initial fractionation of Callophycus serratus extract by liquid-liquid partitioning. Liquid chromatography-mass spectrometry (LC-MS) was applied to identify fractions with isotopic signatures or molecular masses corresponding to putative brominated $\mathrm{C}_{27}$ natural products analogous to diterpene-benzoate macrolides isolated from a previous $C$. serratus collection. ${ }^{2,3}$ Reversed and normal-phase high-performance liquid chromatography (HPLC) separation of these fractions led to isolation of callophycoic acids A-H (1-8) and callophycols A and B (9 and 10).

High-resolution mass spectral data established the molecular formula of callophycoic acid A (1) as $\mathrm{C}_{27} \mathrm{H}_{35} \mathrm{O}_{3} \mathrm{Br}\left(\mathrm{m} / Z 485.1697[\mathrm{M}-\mathrm{H}]^{-}\right)$. X-ray diffraction analysis of $\mathbf{1}$ revealed two identical tricyclic diterpene-benzoic acids in the asymmetric unit, with one having the end of its pendant carbon chain rotated with respect to the other (Figure 1). A Flack parameter of 0.021 (7) supported assignment of $6 R, 7 S$, and $24 S$ absolute stereochemistries for 1 and indicated an $E$ configuration at $\Delta^{10,11}$ and $\Delta^{21,22}$ (Supporting Information), assignments supported by NMR spectral data. Analysis of ${ }^{13} \mathrm{C}$ chemical shifts and $\mathrm{HMBC}$ correlations established the aryl moiety of this 3,4-substituted benzoic acid-based molecule, a structural theme common to 1-7, and a combination of HMBC and COSY correlations established connectivity throughout the tricyclic ring system (Table 1; Supporting Information). Finally, the linear diterpene head was assembled primarily with strong two- and three-bond HMBC correlations from singlet methyl protons.

For callophycoic acid B (2), mass spectral analysis indicated an isotopic splitting pattern identical with that of $\mathbf{1}$ and an $\mathrm{m} / \mathrm{z}[\mathrm{M}-\mathrm{H}]^{-}$of 485.1665 , supporting a molecular formula of $\mathrm{C}_{27} \mathrm{H}_{35} \mathrm{O}_{3} \mathrm{Br}$, isomeric to 1 . Analysis of ${ }^{13} \mathrm{C}$ NMR spectral data indicated significant differences at C-20 ( $\delta 74.7$ for $\mathbf{1} ; \delta 140.2$ for 2 ), C-21 ( $\delta 137.6$ for $\mathbf{1} ; \delta 121.1$ for $\mathbf{2}$ ), and C-22 ( $\delta 122.9$ for $\mathbf{1} ; \delta 33.1$ for 2 ) (Table 1). Further, DEPT-135 data for $\mathbf{1}$ showed that two protons $(\delta 4.42, \delta 4.85)$ were attached at C-20, wile this position in $\mathbf{2}$ possessed a single, more deshielded proton ( $\delta 6.53)$. Conversely, at $\mathrm{C}-22,1$ had one directly attached, deshielded proton ( $\delta 5.56$ ), while 2 had two attached protons ( $\delta 1.90, \delta 2.04)$. This suggested the $\Delta^{21,22}$ olefin in $\mathbf{1}$ was isomerized to a $\Delta^{20,21}$ olefin in $\mathbf{2}$, and the close correspondence of 2D correlations between $\mathbf{1}$ and $\mathbf{2}$ confirmed this conclusion (Supporting Information).

Observed NOEs were similar for $\mathbf{1}$ and $\mathbf{2}$, leading us to predict that these molecules share the same absolute stereochemistry (Supporting Information). Specifically, a strong NOE was noted between H-6 ( $\delta 2.42)$ and H-24 ( $\delta 4.30)$, supporting $6 R$ and $24 S$ configurations for 2. The lack of an observable NOE from either H-6 or H-24 to Me-25 ( $\delta 0.95)$ further supported these configurations and prompted assignment of a $7 S$ configuration. An $E$ configuration was supported at the $\Delta^{10,11}$ olefin of 2 by NOEs observed between Me-26 ( $\left.\delta 1.69\right)$ and H-9b $(\delta 2.05)$ and between $\mathrm{H}-10(\delta$ 5.20) and H-12 ( $\delta$ 2.02) and confirmed by the lack of an NOE between Me-26 and H-10. An $E$ configuration was assigned at the $\Delta^{20,21}$ olefin based on similar arguments. 
Callophycoic acid C (3) gave a mass spectral parent ion at $\mathrm{m} / z$ 581.0895, supporting a molecular formula of $\mathrm{C}_{27} \mathrm{H}_{36} \mathrm{O}_{4} \mathrm{Br}_{2}$. Callophycoic acid $\mathrm{A}(\mathbf{1})$ and $\mathbf{3}$ exhibited nearly identical ${ }^{1} \mathrm{H}$ and ${ }^{13} \mathrm{C}$ chemical shifts and 2D NMR correlations for $\mathrm{C}-1$ through $\mathrm{C}-8$ and C-17 through C-25 (Table 1; Supporting Information), indicating these molecules shared a common tricyclic structure. However, substantial differences in chemical shifts and 2D NMR correlations were found in the diterpenoid head. Assessment of sites of unsaturation indicated that this group included one more ring system than $\mathbf{1}$ and $\mathbf{2}$.

For 3, COSY correlations were observed between H-8 $(\delta 1.78, \delta 2.16)$ and H-9 $(\delta 1.41, \delta$ 1.46), establishing connectivity between these methylenes. Likewise, COSY correlations between $\mathrm{H}-9$ and $\mathrm{H}-10(\delta 1.29)$ established connectivity between these carbons, an assignment further supported by an HMBC correlation from H-10 to C-9 $(\delta 20.8)$. This proton also exhibited HMBC correlations to quaternary C-11 ( $\delta$ 73.0) and C-15 ( $\delta 41.6)$, and methyl C-16 ( $\delta 30.8$ ), establishing $\mathrm{C}-11-\mathrm{C}-10-\mathrm{C}-15-\mathrm{C}-16$ connectivity.

In 3, the singlets Me-16 $(\delta 1.16)$ and Me-27 ( $\delta$ 0.87) shared identical HMBC correlations to $\mathrm{C}-10(\delta 57.6), \mathrm{C}-14(\delta 68.9)$, and $\mathrm{C}-15$, as well as to each other. These correlations were thus a starting point for establishing connectivity within spin systems of the cyclohexanol ring through COSY and additional HMBC correlations. Hydroxy and bromine groups were assigned at C-11 and C-14, respectively, on the basis of carbon and proton chemical shift arguments. ${ }^{4}$

NOEs for the tricyclic moiety of $\mathbf{3}$ matched closely those of $\mathbf{1}$ (Supporting Information), leading us to predict $6 R, 7 S$, and $24 S$ absolute configurations, as in $\mathbf{1}$ and $\mathbf{2}$. Relative stereochemistry within the cyclohexanol ring was then established based on observed NOEs. First, $\mathrm{H}-10$ and H-14 were assigned to diaxial positions on the same face of the ring, due to NOEs observed between these protons. Further, the diaxial orientation of these protons supported a chair conformation for the cyclohexanol ring, with the bulky alkyl substituent on $\mathrm{C}-10$ and bromine on $\mathrm{C}-14$ assuming equatorial positions. Me-16 was then assigned to an equatorial position on the same face as $\mathrm{H}-10$ and H-14, based on NOEs between both of these protons and Me-16, an assignment further supported by the lack of NOEs between H-10 or H-14 and axial Me-27. Finally, Me-26 was assigned an axial position on the opposite side of the ring to H-10 and H-14, based upon an NOE between Me-26 and Me-27, and supported by the absence of an NOE between Me-26 and H-10 or H-14.

With the relative stereochemistry of the cyclohexanol moiety of $\mathbf{3}$ elucidated, the absolute stereochemistry of this ring was determined with a series of NOEs that established the orientation of this ring relative to the $6 R, 7 S, 24 S$ tricycle (Figure 2). First, the conformation of the bond between C-9 and C-10 was determined by NOEs between H-9a and both Me-16 and Me-27, which supported H-9a pointing toward these two methyls. This assignment was further supported by the lack of an NOE between H-9a and Me-26. An NOE between H-9b and Me-26, but not between $\mathrm{H}-9 \mathrm{~b}$ and Me-16 or Me-27, analogously prompted placement of H-9b pointing toward Me-26. Next, NOEs were observed between H-9a and H-24 and between H-9b and H-6, supporting a conformational preference of H-9a, Me-16, H-24, and Me-27 on one side of the molecule and H-9b, H-6, and Me-26 on the other side. On the basis of these correlations, a $10 S, 11 S, 14 S$ stereochemistry was assigned for the cyclohexanol ring (Figure 2, left). The enantiomer $(10 R, 11 R, 14 R)$ should instead afford NOEs between $\mathrm{H}-9 \mathrm{~b}$ and $\mathrm{H}-24$ and between H-9a and H-6, but these correlations were not observed (Figure 2 , right), thus confirming the cyclohexanol stereochemistry. With this distinctive ring system different from callophycoic acids A and B (1 and $\mathbf{2}$ ), $\mathbf{3}$ provided a second novel carbon skeleton. 
Callophycoic acid D (4) appeared structurally similar to 3, with an identical molecular formula $\left(\mathrm{C}_{27} \mathrm{H}_{36} \mathrm{O}_{4} \mathrm{Br}_{2}\right.$ from $[\mathrm{M}-\mathrm{H}]^{-} \mathrm{m} / z$ 581.0889). The major difference between 3 and 4 occurred in the tricyclic moiety. ${ }^{1} \mathrm{H}$ and ${ }^{13} \mathrm{C}$ chemical shifts, DEPT-135 data, and HMBC and COSY correlations for this group closely matched those observed for $\mathbf{2}$, prompting assignment of a tricycle identical with that of $\mathbf{2}$. Hence, like $\mathbf{1}$ and $\mathbf{2}$, callophycoic acids $\mathrm{C}$ and D (3 and 4) are isomers, differing only in the position of the olefin $\left(\Delta^{21,22}\right.$ in $\mathbf{1}$ and $\mathbf{3}$ and $\Delta^{20,21}$ in 2 and $\mathbf{4}$ ). The stereochemistry of $\mathbf{4}$ was established as $6 R, 7 S, 10 S, 11 S, 14 S$, $24 S$ and the $\Delta^{20,21}$ olefin was assigned a cis conformation on the basis of NOE arguments analogous to those for $\mathbf{3}$.

Comparison of NMR spectral data suggested that callophycoic acid E (5), with a parent ion of $\mathrm{m} / z 563.0807$ (suitable for a molecular formula of $\mathrm{C}_{27} \mathrm{H}_{34} \mathrm{O}_{3} \mathrm{Br}_{2}$ ), was most similar to 4, with similar ${ }^{13} \mathrm{C}$ and ${ }^{1} \mathrm{H}$ chemical shifts and $2 \mathrm{D}$ correlations throughout the tricyclic group. Further, spectral data were largely similar within the cyclohexane moiety, with the primary difference being the presence of an exo-methylene in $\mathbf{5}$ instead of the methyl and hydroxy groups observed in 4 . Assignment of the $\Delta^{11,26}$ olefin was confirmed by HMBC correlations from $\mathrm{H}-26(\delta 4.84, \delta 5.13)$ to $\mathrm{C}-10(\delta 53.9)$ and C-12 ( $\delta$ 35.7). Chemical shift assignments within the methylenecyclohexane system of $\mathbf{5}$ were further supported by close correspondence with previous reports of this group. ${ }^{5}$ The stereochemistry of the tricyclic system was established as $6 R, 7 S, 24 S$ on the basis of NOE arguments analogous to those for 1-4. NOEs for 5 did not permit determination of the stereochemistry of the methylenecyclohexane ring relative to the tricyclic moiety, but, given the similarity between $\mathbf{3}, \mathbf{4}$, and $\mathbf{5}$, stereochemistry within this group was proposed as $10 S, 14 S$, and supported by NOEs between $\mathrm{H}-10(\delta 1.79)$ and $\mathrm{H}-14(\delta 4.17)$ and between both $\mathrm{H}-10$ and $\mathrm{H}-14$ and Me-16.

High-resolution mass spectral analysis established a molecular formula of $\mathrm{C}_{27} \mathrm{H}_{36} \mathrm{O}_{3}(\mathrm{~m} / Z$ $407.2574[\mathrm{M}-\mathrm{H}]^{-}$) for callophycoic acid $\mathrm{F}(6)$. Comparison of ${ }^{1} \mathrm{H}$ and ${ }^{13} \mathrm{C}$ chemical shifts and HMBC and COSY correlations between 1-5 and 6 indicated that this molecule contained a benzoic acid functionality fused to an unsaturated seven-membered ether ring. However, HMBC and COSY correlations indicated regioisomerization of the olefin relative to 1-5. For 6, HMBC correlations from H-5 ( $\delta 3.48)$ to olefinic carbons C-6 ( $\delta 121.7)$ and C-7 ( $\delta$ 137.9) supported a $\Delta^{6,7}$ olefin. This assignment was verified and the sevenmembered ether ring sealed by HMBC correlations from $\mathrm{H}-24(\delta 4.56)$ to $\mathrm{C}-7$. HMBC correlations from H-6 and H-24 to C-8 ( $\delta 34.8)$ connected the ring system to the side chain. This C-7-C-8 linkage completed one isoprene unit and left three sites of unsaturation, accounted for by six additional olefin signals evident from the ${ }^{13} \mathrm{C}$ NMR spectrum.

For 6, the COSY correlation between H-9 ( $\delta$ 2.04) and H-10 $(\delta 5.05)$ and HMBC correlations from $\mathrm{H}-10$ to $\mathrm{C}-8$ and C-9 $(\delta$ 26.7) prompted placement of C-9 between C-8 and C-10 ( $\delta$ 123.3). Strong two- and three-bond HMBC correlations from the Me-25 singlet $(\delta$ 1.53 ) to $\mathrm{C}-10$ and $\mathrm{C}-11$ ( $\delta$ 135.9) supported linkage of these two olefinic carbons, with $\mathrm{C}-11$ bearing the methyl substituent; an additional HMBC correlation between Me-25 and C-12 $(\delta$ 39.7) established the connectivity of C-11 with C-12 and completed the second isoprene unit. The third and fourth isoprene units were then assembled on the basis of similar arguments. Assignments of ${ }^{1} \mathrm{H}$ and ${ }^{13} \mathrm{C}$ chemical shifts in this linear terpenoid head were verified by comparison with literature values for analogous moieties. ${ }^{6}$

An $E$-configuration was established for the $\Delta^{10,11}$ olefin of 6 based on NOEs from Me-25 to $\mathrm{H}-9$ and the lack of an NOE between Me-25 and H-10. An E-configuration was proposed at the $\Delta^{14,15}$ olefin based on similar arguments. The carbon skeleton of $\mathbf{6}$ is not novel, matching that of common tocopherols. ${ }^{7}$ 
From high-resolution mass spectral data, the molecular formula of callophycoic acid $\mathrm{G}$ (7) was established as $\mathrm{C}_{27} \mathrm{H}_{37} \mathrm{O}_{3}-\mathrm{Br}\left(\mathrm{m} / z 487.1823[\mathrm{M}-\mathrm{H}]^{-}\right)$. As for $1-6,{ }^{1} \mathrm{H},{ }^{13} \mathrm{C}$, COSY, and $\mathrm{HMBC}$ data were indicative of a disubstituted benzoic acid moiety linked to a diterpene (Table 1; Supporting Information). Unlike 1-6, 7 presented a phenolic-OH signal ( $\delta 5.45$ ), which was assigned as the $\mathrm{C}-19$ substituent as for bromophycolides. ${ }^{2,3}$ The possibility of a seven-membered ether ring, as in previous compounds, was thus eliminated.

Elucidation of the decalin system of 7 commenced with singlets Me-25 ( $\delta$ 0.87) and Me-26 ( $\delta 0.94)$, for which all expected two- and three-bond HMBC correlations were observed, thus establishing connectivity along positions C-6-C-7-C-24-C-11-C-10 of the decalin group and supporting bonds between $\mathrm{C}-7-\mathrm{C}-8$ and $\mathrm{C}-11-\mathrm{C}-12$. COSY correlations were observed between $\mathrm{H}-24(\delta 1.54)$ and $\mathrm{H}-23 \mathrm{~b}(\delta 1.72)$, and between $\mathrm{H}-22(\delta 2.03, \delta 2.38)$ and $\mathrm{H}-23(\delta 1.48, \delta 1.72)$, thus establishing C-22-C-23-C-24 connectivity. HMBC correlations from exo-methylenes $\mathrm{H}-21 \mathrm{a}(\delta 4.68)$ and $\mathrm{H}-21 \mathrm{~b}(\delta 4.82)$ to $\mathrm{C}-22(\delta 37.7)$ and $\mathrm{C}-6(\delta 55.6)$ then supported connection of $\mathrm{C}-22-\mathrm{C}-20-\mathrm{C}-6$, thus sealing this ring. To seal the second ring of the decalin system of 7, C-8-C-9-C-10 connectivity was established on the basis of COSY correlations between H-8 $(\delta 1.38, \delta 1.91)$ and H-9 $(\delta 2.19, \delta 2.27)$, and between C-9 protons and $\mathrm{H}-10(\delta 4.32)$. Assignments in the decalin system were verified by comparison with literature values for analogous moieties. ${ }^{8,9}$ The isoprenoid head of 7 was next established with COSY and HMBC correlations, analogously to 1-6.

The relative stereochemistry of 7 was determined from NOE correlations (Supporting Information). Observation of an NOE between $\mathrm{H}-6(\delta 2.25)$ and $\mathrm{H}-24$ and between $\mathrm{H}-24$ and $\mathrm{H}-10$ indicated that these protons were positioned on the same face of the decalin ring system. Observation of an NOE between Me-25 and Me-26, but not between either of these groups and H-6 or H-10, next supported placement of these methyls cis on the other face. The absolute stereochemistry was left unassigned.

Callophycoic acid $\mathrm{H}(\mathbf{8})$ possessed a molecular formula of $\mathrm{C}_{27} \mathrm{H}_{36} \mathrm{O}_{3} \mathrm{Br}_{2}(\mathrm{~m} / z 565.0968[\mathrm{M}$ $-\mathrm{H}]^{-}$). Comparison of ${ }^{1} \mathrm{H}$ and ${ }^{13} \mathrm{C}$ chemical shifts (Table 1) and 2D correlations (Supporting Information) between callophycoic acids $\mathrm{G}$ and $\mathrm{H}$ (7 and $\mathbf{8}$ ) indicated these molecules differed by one bromine atom within the aryl ring, with $\mathbf{8}$ including a trisubstituted benzoic acid in contrast to the disubstituted moiety of 7 . The substitution pattern of this aryl ring was determined by HMBC correlations from aryl protons and confirmed by comparison of ${ }^{13} \mathrm{C}$ chemical shifts with empirical values. ${ }^{4}$ Together, callophycoic acids $\mathrm{G}$ and $\mathrm{H}$ (7 and $\mathbf{8}$ ) represent a third novel carbon skeleton.

High-resolution mass spectrometry and ${ }^{1} \mathrm{H}$ and ${ }^{13} \mathrm{C}$ NMR spectra indicated that callophycol A (9) had a molecular formula of $\mathrm{C}_{26} \mathrm{H}_{35} \mathrm{OBr}_{4} \mathrm{Cl}\left(\mathrm{m} / z 712.9066[\mathrm{M}-\mathrm{H}]^{-}\right)$, one fewer carbons than 1-8. With only one oxygen atom, this molecular formula did not support the carboxylic acid functionality observed in 1-8, suggesting the missing carbon was in this functional group, a hypothesis supported by the absence of a diagnostic carboxylic acid signal in the ${ }^{13} \mathrm{C}$ NMR spectrum for 9 and confirmed by the lack of a characteristic carbonyl stretching absorption in the IR spectrum, compared to the strong IR absorbance at 1687 $\mathrm{cm}^{-1}$ for $\mathbf{1}$.

${ }^{1} \mathrm{H},{ }^{13} \mathrm{C}$, and $\mathrm{HMBC}$ NMR spectral data were applied in elucidating the dibromophenol of 9 (Table 2; Supporting Information). HMBC correlations were observed from the aryl hydroxy proton ( $\delta 5.60)$ to $\mathrm{C}-1$ ( $\delta 149.3), \mathrm{C}-2$ ( $\delta 110.7)$, and C-6 ( $\delta 131.3)$, and the downfield shift of $\mathrm{C}-1$ corresponded with literature values for phenolic carbons, ${ }^{4}$ establishing C-2-C-1-C-6 connectivity. HMBC correlations from alkyl H-7 $(\delta 2.73, \delta 2.75)$ to $\mathrm{C}-1, \mathrm{C}-5$ ( $\delta$ 132.1), and C-6 next supported connection of these aryl carbons. HMBC

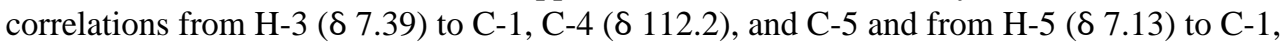


C-3 ( $\delta$ 131.1), and C-4 then established the remaining carbon connectivity within the aryl group. Completion of the aryl framework of 9 left the C-2 and C-4 substituents to be identified as either two bromines or one bromine and one chlorine. Arguments based upon substituent effects on carbon chemical shifts ${ }^{4}$ and comparison with data for 2,4-dibromo-6methylphenol ${ }^{10}$ supported assignment of a dibromonated phenol.

For the remaining portions of $\mathbf{9}$ except for the diterpene head, NMR data were nearly identical with data for $\mathbf{7}$ and $\mathbf{8}$ (Tables 1 and 2; Supporting Information), supporting a decalin system identical with those molecules. At the diterpene head, COSY correlations between $\mathrm{H}-14 \mathrm{a}(\delta 1.38)$ and $\mathrm{H}-15 \mathrm{~b}(\delta 2.26)$ and between $\mathrm{H}-14 \mathrm{~b}(\delta 2.06)$ and both $\mathrm{H}-15$ multiplets supported C-14-C-15 connection. Further, both H-14 protons showed HMBC correlations to methine $\mathrm{C}-16$ ( $\delta 65.5$ ), establishing the $\mathrm{C}-15-\mathrm{C}-16$ linkage, which was verified by a COSY correlation between $\mathrm{H}-15 \mathrm{a}(\delta 1.68)$ and $\mathrm{H}-16(\delta 3.90)$. The carbon skeleton was then completed by HMBC correlations from Me-18 $(\delta 1.79)$ and Me-26 ( $\delta$ $1.70)$ to one another, to $C-16$, and to $C-17$ ( $\delta 72.7)$. The bromine atom was then attached to methine $\mathrm{C}-16$ and the chlorine at quaternary $\mathrm{C}-17$ on the basis of ${ }^{13} \mathrm{C}$ chemical shift predictions ${ }^{4}$ and empirical data, ${ }^{11,12}$ which supported assignment of the chlorine at the more deshielded carbon.

NOEs within the decalin system were analogous for $\mathbf{7 - 9}$, supporting the same relative stereochemistries for all of these molecules. However, an additional stereocenter was introduced at C-16 in 9. Because no NOEs were observed between decalin stereocenters and the stereocenter at $\mathrm{C}-16$, it was left unassigned.

High-resolution mass spectrometry $\left(\mathrm{m} / \mathrm{z} 712.8889[\mathrm{M}-\mathrm{H}]^{-}\right)$indicated 10 shared the $\mathrm{C}_{26} \mathrm{H}_{35} \mathrm{OBr}_{4} \mathrm{Cl}$ molecular formula with 9. Comparison of NMR spectral data for these two molecules indicated differences at C-16 and C-17 (Table 2), with the C-16 methine in $\mathbf{1 0}$ being shifted downfield relative to $\mathbf{9}(\delta 65.5$ in $\mathbf{9}$ vs $\delta 72.7$ in $\mathbf{1 0}$ ), and quaternary C-17 in $\mathbf{1 0}$ shifted upfield relative to $\mathbf{9}$ ( $\delta 72.7$ in $\mathbf{9}$ vs $\delta 68.3$ in 10). This supported chlorination at C-16 and bromination at $\mathrm{C}-17$ in $\mathbf{1 0}$. As with $\mathbf{9}$, the stereochemistry at $\mathrm{C}-16$ was unassigned for 10.

In the biosynthesis of callophycoic acids A-H (1-8) and callophycols A and B (9 and 10), carbon-carbon bond formation between the aromatic moiety and geranylgeranyl diphospate (GPP) likely occurs by electrophilic aromatic substitution, analogously to the pathway hypothesized for 10 bromophycolides (diterpene-benzoate macrolides), including bromophycolides A and B (11 and 12), previously isolated from Callophycus serratus. ${ }^{2,3}$ Among the bromophycolides and currently presented metabolites, callophycols A and B ( 9 and 10) are exceptional in the lack of a benzoic acid-based aromatic moiety; the putative shikimate-based 2,4-dibromophenol group of $\mathbf{9}$ and $\mathbf{1 0}$ was likely introduced during the electrophilic aromatic substitution step of biosynthesis and indicates either a different biosynthetic pathway for $\mathbf{9}$ and $\mathbf{1 0}$ or, more likely, that the enzymes catalyzing this step are flexible in substrate acceptance.

Unlike the bromophycolides, in which electrophilic aromatic substitution was likely followed with esterification to yield 15-and 16-membered lactones (e.g., 11 and 12), callophycoic acids A-H (1-8) maintained their carboxylic acid functional group during biosynthesis. Following electophilic aromatic substitution, the linear diterpene-benzoic acid (in 1-8) or diterpene-phenol (in 9-10) likely underwent a series of hydride shifts, addition, and elimination reactions, characteristic of isoprenoid biosynthesis. ${ }^{13}$ These reactions resulted in halogenation at electrophilic sites expected for vanadium haloperoxidase-based biosynthetic enzymes previously implicated in terpenoid biosynthesis. ${ }^{14}$ Callophycoic acid F (6) is a probable precursor of callophycoic acids A-E (1-5) (Scheme 1), while callophycoic 
acids $\mathrm{G}$ and $\mathrm{H}$ (7and 8) and callophycols A and B (9 and 10) are hypothesized to be formed by an alternative mode of cyclization (Scheme 2). The wide diversity of metabolites produced from diterpene-benzoic acid (in 1-8) or diterpene-phenol (in 9 and 10) precursors suggests either the involvement of a diverse array of enzymes or catalytic promiscuity in the enzymatic machinery that biosynthesizes these metabolites.

LC-MS analysis of the extract from which callophycoic acids A-H (1-8) and callophycols A and B (9 and 10) were isolated indicated no presence of bromophycolides (e.g., $\mathbf{1 1}$ and 12), originally isolated from Callophycus serratus collected at a different Fijian site. Likewise, LC-MS analysis of the extract containing bromophycolides showed no indication of callophycoic acids or callophycols. This may suggest that different populations of this red alga possess different genotypes, only one of which produces the enzymes necessary for lactonization. Alternatively, environmental differences between the two collection sites may have resulted in production of different metabolites due to induction or related mechanisms. Another possibility is that specimens collected at these two sites represent different, closely related species that fit within the present description of $C$. serratus. ${ }^{20}$

In addition to the structural novelty of callophycoic acids A-H (1-8) and callophycols A and B (9 and 10), compounds in this group demonstrated modest antimalarial, antibacterial, anticancer, and antifungal activities (Table 3). Antibacterial activity was somewhat targeted, with regioisomers $\mathbf{1}$ and $\mathbf{2}$ each inhibiting Enterococcus faecium, but being inactive against Staphylococcus aereus. In contrast, regioisomers $\mathbf{3}$ and $\mathbf{4}$ were more active against $S$. aureus than against $E$. faecium.

To our knowledge, the eight callophycoic acids (1-8) presented herein provide the first reports of macroalgal diterpene-benzoic acids, as this group of compounds was previously reported exclusively in terrestrial cyanobacteria. ${ }^{15-17}$ The two callophycols (9 and 10) represent an even more unusual class of compounds, with no previous reports of halogenated diterpene phenols, to our knowledge. Considered together, the 20 bromophycolides, callophycoic acids, and callophycols more than quadruple the number of secondary metabolites previously isolated from members of the algal family

Solieriaceae, ${ }^{18,19}$ and suggest evaluation of additional members of this group, and also additional populations of $C$. serratus, may provide additional structurally novel bioactive compounds.

\section{Experimental Section}

\section{Biological Material}

Callophycus serratus (Harvey ex Kutzing 1957) (family Solieriaceae, order Gigartinales, class Rhodophyceae, phylum Rhodophyta) was collected at depths from 9 to $15 \mathrm{~m}$ near Harold's Passage, Astrolobe Reef, Kadavu Province, Fiji (18 46 $37^{\prime \prime}$ S, $178^{\circ} 27^{\prime} 74^{\prime \prime}$ E). Material was identified by comparison with previously described morphological traits ${ }^{20}$ and frozen at $-20{ }^{\circ} \mathrm{C}$ until extraction. A voucher specimen is deposited at the University of the South Pacific.

\section{Pharmacological Assays}

Bioassay-guided fractionation was directed by a sublethal rotifer ingestion toxicity assay with the freshwater species Brachionus calyciflorus, as previously described. ${ }^{2,21}$ Isolated compounds were evaluated against a panel of tumor cell lines including breast, colon, lung, prostate, and ovarian cancer cells. Specific cell lines were the following: BT-549, DU4475, MDA-MD-468, NCI-H446, PC-3, SHP-77, LNCaP-FGC, HCT116, MDA-MB-231, A2780/ DDP-S, and Du145. In vitro cytotoxicity was tested with the (3-(4,5-dimethylthiazol-2yl)-5-(3-carboxylmethoxyphenyl)-2-(4-sulfophenyl)-2 $H$-tetrazolium inner salt) MTS dye 
conversion assay as described previously. ${ }^{22}$ Antibacterial assays were performed against Staphylococcus aureus (ATCC \#10537) and Enterococcus faecium (ATCC \#12952) as previously described. ${ }^{3}$ Antifungal assays were performed against amphotericin B-resistant Candida albicans as previously described. ${ }^{3}$

Antitubercular activity was assessed against Mycobacterium tuberculosis strain $\mathrm{H}_{37} \mathrm{Rv}$ (ATCC 27294), using the alamar blue susceptibility test (MABA) as described previously. ${ }^{23}$ Compounds 1-6 were tested at a maximum concentration of $100 \mathrm{uM}, 8$ at a maximum concentration of $50 \mathrm{uM}$, and $\mathbf{7}$ and $\mathbf{1 0}$ at a maximum concentration of $10 \mathrm{uM}$. The MIC was reported as the lowest concentration of a serial dilution series resulting in $\searrow 90 \%$ growth inhibition relative to controls. Antimalarial activity was determined with a SYBR Green based parasite proliferation assay, adapted from Smilkstein ${ }^{24}$ and Bennett. ${ }^{25}$ Briefly, Plasmodium falciparum parasites (3D7 strain MR4/ATCC, Manassas, VA) were cultured in human $\mathrm{O}+$ erythrocytes as previously described. ${ }^{26}$ Compounds were diluted in complete medium and $40 \mu \mathrm{L}$ transferred to 96 -well assay plates. To this $80 \mu \mathrm{L}$ of complete media with 3D7 infected erythrocytes was dispensed to obtain a $2.5 \%$ hematocrit and $0.5 \%$ parasitemia in the assay. Uninfected erythrocytes were dispensed into the background wells at the same final hematocrit. Plates were incubated for $72 \mathrm{~h}$ in a low oxygen environment $\left(96 \% \mathrm{~N}_{2}, 3 \% \mathrm{CO}_{2}, 1 \% \mathrm{O}_{2}\right)$ in a modular incubation chamber. The plates were sealed and placed in a $-80{ }^{\circ} \mathrm{C}$ freezer overnight then thawed, and $120 \mu \mathrm{L}$ of lysis buffer $(20 \mathrm{mM}$ Tris$\mathrm{HCl}, \mathrm{pH} 7.5,5 \mathrm{mM}$ EDTA, $0.08 \%$ Triton X-100, $0.008 \%$ saponin with $0.2 \mu \mathrm{L} / \mathrm{mL}$ Sybr Green I) was dispensed into each well and incubated at $37^{\circ} \mathrm{C}$ in the dark for $6 \mathrm{~h}$ to achieve maximum signal-to-noise ratio. The plates were read with a Molecular Devices SpectraMAX Gemini EM at ex $495 \mathrm{~nm}$ and em $525 \mathrm{~nm}$ with $515 \mathrm{~nm}$ cutoff.

\section{Isolation}

Callophycus serratus was exhaustively extracted with water, methanol, and methanol/ dichloromethane (1:1 and 1:2). Extracts were combined, filtered, and concentrated in vacuo. This crude extract was partitioned between methanol/water (9:1) and petroleum ether. The aqueous fraction was adjusted to methanol/water (3:2) and partitioned against chloroform. This bioactive chloroform extract was fractionated into 1-10 by multiple rounds of $\mathrm{C}_{18}$ reversed-phase HPLC, using gradients of methanol/water and acetonitrile/water with an Agilent Zorbax SB-C 18 column, followed by normal-phase HPLC, using a hexanes/ethyl acetate gradient with an Agilent Zorbax RX-SIL column.

Callophycoic acid A (1)—clear crystalline solid (9.8 mg; $0.037 \%$ plant dry mass); $[\mathrm{a}]^{24} \mathrm{D}$ -115 (c $0.13 \mathrm{~g} / 100 \mathrm{~mL}, \mathrm{MeOH})$; UV (MeOH) $\lambda_{\max }(\log \epsilon) 258(3.70) \mathrm{nm}$; for ${ }^{1} \mathrm{H}$ and ${ }^{13} \mathrm{C}$ NMR data see Table 1; for COSY, HMBC, and NOE data see the Supporting Information; HR ESI-MS $\mathrm{m} / \mathrm{z} 485.1697[\mathrm{M}-\mathrm{H}]^{-}$(calcd for $\mathrm{C}_{27} \mathrm{H}_{34} \mathrm{O}_{3} \mathrm{Br}$, 485.1691).

Callophycoic acid B (2)—white amorphous solid (12.0 mg; $0.046 \%$ plant dry mass); $[a]^{24}{ }_{\mathrm{D}}+165$ (c $\left.0.071 \mathrm{~g} / 100 \mathrm{~mL}, \mathrm{MeOH}\right) ; \mathrm{UV}(\mathrm{MeOH}) \lambda_{\max }(\log \epsilon) 260(3.64) \mathrm{nm}$; for ${ }^{1} \mathrm{H}$ and ${ }^{13} \mathrm{C}$ NMR data see Table 1; for COSY, HMBC, and NOE data see the Supporting Information; HR ESI-MS m/z $485.1665[\mathrm{M}-\mathrm{H}]^{-}$(calcd for $\mathrm{C}_{27} \mathrm{H}_{34} \mathrm{O}_{3} \mathrm{Br}, 485.1691$ ).

Callophycoic acid C (3)—white amorphous solid (2.5 mg, 0.009\% plant dry mass); $[a]^{24}{ }_{D}-49(c 0.031 \mathrm{~g} / 100 \mathrm{~mL}, \mathrm{MeOH}) ; \mathrm{UV}(\mathrm{MeOH}) \lambda_{\max }(\log \in) 258(4.03) \mathrm{nm}$; for ${ }^{1} \mathrm{H}$ and ${ }^{13} \mathrm{C}$ NMR $\left(\left(\mathrm{CD}_{3}\right)_{2} \mathrm{CO}, 500 \mathrm{MHz}\right)$ data see Table 1 ; for COSY, HMBC, and NOE data see the Supporting Information; HR ESI-MS $[\mathrm{M}-\mathrm{H}]^{-} \mathrm{m} / z 581.0895$ (calcd for $\mathrm{C}_{27} \mathrm{H}_{35} \mathrm{O}_{4} \mathrm{Br}_{2}$, 581.0902). 
Callophycoic acid D (4)—white amorphous solid (1.6 mg, 0.006\% plant dry mass); $[a]^{24} \mathrm{D}+85(c 0.018 \mathrm{~g} / 100 \mathrm{~mL}, \mathrm{MeOH}) ; \mathrm{UV}(\mathrm{MeOH}) \lambda_{\max }(\log \epsilon) 258(3.81) \mathrm{nm}$; for ${ }^{1} \mathrm{H}$ and ${ }^{13} \mathrm{C}$ NMR $\left(\left(\mathrm{CD}_{3}\right)_{2} \mathrm{CO}, 500 \mathrm{MHz}\right)$ data see Table 1; for COSY, HMBC, and NOE data see the Supporting Information; HR ESI-MS $[\mathrm{M}-\mathrm{H}]^{-} \mathrm{m} / z 581.0889$ (calcd for $\left.\mathrm{C}_{27} \mathrm{H}_{35} \mathrm{O}_{4} \mathrm{Br}_{2}, 581.0902\right)$.

Callophycoic acid E (5)—white amorphous solid (1.9 mg; $0.007 \%$ plant dry mass); $[a]^{24}+117$ (c $\left.0.031 \mathrm{~g} / 100 \mathrm{~mL}, \mathrm{MeOH}\right) ; \mathrm{UV}(\mathrm{MeOH}) \lambda_{\max }(\log \epsilon) 227$ (3.70) nm; for ${ }^{1} \mathrm{H}$ and ${ }^{13} \mathrm{C}$ NMR data see Table 1; for COSY, HMBC, and NOE data see the Supporting Information; HRESIMS $\mathrm{m} / \mathrm{z} 563.0807[\mathrm{M}-\mathrm{H}]^{-}$(calcd for $\mathrm{C}_{27} \mathrm{H}_{33} \mathrm{O}_{3} \mathrm{Br}_{2}$, 563.0800).

Callophycoic acid F (6)—white amorphous solid (6.0 mg; $0.023 \%$ plant dry mass); UV $(\mathrm{MeOH}) \lambda_{\max }(\log \epsilon) 246(3.08) \mathrm{nm}$; for ${ }^{1} \mathrm{H}$ and ${ }^{13} \mathrm{C}$ NMR data see Table 1; for COSY, HMBC, and NOE data see the Supporting Information; HRESIMS $m / z 407.2574[\mathrm{M}-\mathrm{H}]^{-}$ (calcd for $\mathrm{C}_{27} \mathrm{H}_{35} \mathrm{O}_{3}, 407.2586$ ).

Callophycoic acid G (7)—white amorphous solid (1.0 mg; 0.004\% plant dry mass); $[a]^{24} \mathrm{D}+137(c 0.018 \mathrm{~g} / 100 \mathrm{~mL}, \mathrm{MeOH}) ; \mathrm{UV}(\mathrm{MeOH}) \lambda_{\max }(\log \epsilon) 258(3.88) \mathrm{nm}$; for ${ }^{1} \mathrm{H}$ and ${ }^{13} \mathrm{C}$ NMR data see Table 1; for COSY, HMBC, and NOE data see the Supporting Information; HRESIMS $\mathrm{m} / z$ 487.1823 [M - H] ${ }^{-}$(calcd for $\mathrm{C}_{27} \mathrm{H}_{36} \mathrm{O}_{3} \mathrm{Br}, 487.1853$ ).

Callophycoic acid H (8)—white amorphous solid (2.4 mg; $0.009 \%$ plant dry mass); $[a]^{24} \mathrm{D}+99(c 0.024 \mathrm{~g} / 100 \mathrm{~mL}, \mathrm{MeOH}) ; \mathrm{UV}(\mathrm{MeOH}) \lambda_{\max }(\log \epsilon) 258(3.72) \mathrm{nm}$; for ${ }^{1} \mathrm{H}$ and ${ }^{13} \mathrm{C}$ NMR data see Table 1; for COSY, HMBC, and NOE data see the Supporting Information; HRESIMS m/z $565.0968[\mathrm{M}-\mathrm{H}]^{-}$(calcd for $\mathrm{C}_{27} \mathrm{H}_{35} \mathrm{O}_{3} \mathrm{Br}_{2}, 565.0958$ ).

Callophycol A (9)—white amorphous solid (2.5 mg; $0.009 \%$ plant dry mass); [a $]^{24} \mathrm{D}+75$ (c $0.029 \mathrm{~g} / 100 \mathrm{~mL}, \mathrm{MeOH})$; UV (MeOH) $\lambda_{\max }(\log \epsilon) 229$ (4.11) nm; for ${ }^{1} \mathrm{H}$ and ${ }^{13} \mathrm{C}$ NMR data see Table 2; for COSY, HMBC, and NOE data see the Supporting Information; HRESIMS m/z $712.9066[\mathrm{M}-\mathrm{H}]^{-}$(calcd for $\mathrm{C}_{26} \mathrm{H}_{34} \mathrm{OBr}_{4} \mathrm{Cl}, 712.9032$ ).

Callophycol B (10)—white amorphous solid (2.2 mg; $0.008 \%$ plant dry mass); [a $]^{24} \mathrm{D}$ $+110(c 0.018 \mathrm{~g} / 100 \mathrm{~mL}, \mathrm{MeOH}) ; \mathrm{UV}(\mathrm{MeOH}) \lambda_{\max }(\log \epsilon) 229(4.04) \mathrm{nm}$; for ${ }^{1} \mathrm{H}$ and ${ }^{13} \mathrm{C}$ NMR data see Table 2; for COSY, HMBC, and NOE data see the Supporting Information; HRESIMS $\mathrm{m} / z 712.8889[\mathrm{M}-\mathrm{H}]^{-}$(calcd for $\mathrm{C}_{26} \mathrm{H}_{34}-\mathrm{OBr}_{4} \mathrm{Cl}, 712.9032$ ).

\section{Supplementary Material}

Refer to Web version on PubMed Central for supplementary material.

\section{Acknowledgments}

This work was supported by ICBG grant No. 1 U01 TW007401-01 from the Fogarty International Center of the U.S. National Institutes of Health, by NSF-IGERT and GAANN predoctoral fellowships to A.L.L, and by a GAANN predoctoral fellowship to E.P.S. The authors thank the Government of Fiji for permission to perform research in their territorial waters, and the people of Kadavu, Nadroga, and Rewa provinces for facilitating this work. We especially thank Ratu Kitione Qereqeretabua and the residents of Dravuni village for hosting visits to their island and reefs, making this research possible. We thank R. Peterson and K. Johnston at Bristol-Myers Squibb for antitumor assays; L. Mylacraine for antibacterial assays; S. Kelly and C. Boonlarpradab for antifungal assays; M. C. Sullards and D. Bostwick for mass spectral analyses; L. Gelbaum for NMR assistance; R.W. Jiang for assistance analyzing X-ray data; A. Bommarius and T. Thaler for use of their spectropolarimeter; U. Bunz and S. Miao for use of their IR spectrometer; A. Chequer, H. Hay, and K. Hay for field assistance; and, M. Sharma and K. Feussner for assistance with extractions. 


\section{References}

(1). Blunt JW, Copp BR, Munro MHG, Northcote PT, Prinsep MR. Nat. Prod. Rep. 2005; 22:15-61. [PubMed: 15692616]

(2). Kubanek J, Prusak AC, Snell TW, Giese RA, Fairchild CR, Aalbersberg W, Hay ME. J. Nat. Prod. 2006; 69:731-735. [PubMed: 16724831]

(3). Kubanek J, Prusak AC, Snell TW, Giese RA, Hardcastle KI, Fairchild CR, Aalbersberg W, Raventos-Suarez C, Hay ME. Org. Lett. 2005; 7:5261-5264. [PubMed: 16268553]

(4). Silverstein, RM.; Webster, FX. Spectrometric Identification of Organic Compounds. 6th ed.. John Wiley \& Sons, Inc.; New York: 1998.

(5). Kuniyoshi M, Marma MS, Higa T, Bernardinelli G, Jefford CW. J. Nat. Prod. 2001; 64:696-700. [PubMed: 11421726]

(6). Ito H, Onoue S, Miyake Y, Yoshida T. J. Nat. Prod. 1999; 62:89-93. [PubMed: 9917289]

(7). Shin TS, Godber JS. J. Chromatogr. A. 1994; 678:49-58.

(8). West LM, Faulkner DJ. J. Nat. Prod. 2006; 69:1001-1004. [PubMed: 16872132]

(9). Cavin AL, Hay AE, Marston A, Stoeckli-Evans H, Scopelliti R, Diallo D, Hostettmann K. J. Nat. Prod. 2006; 69:768-773. [PubMed: 16724838]

(10). Maloney DJ, Hecht SM. Org. Lett. 2005; 7:4297-4300. [PubMed: 16146411]

(11). Suzuki M, Matsuo Y, Takeda S, Suzuki T. Phytochemistry. 1993; 33:651-656.

(12). Wright AD, Konig GM, Sticher O, Denys R. Tetrahedron. 1991; 47:5717-5724.

(13). Herbert, RB., editor. The Biosynthesis of Secondary Metabolites. 2nd ed.. Chapman \& Hall; London, UK: 1989.

(14). Butler A, Carter-Franklin JN. Nat. Prod. Rep. 2004; 21:180-188. [PubMed: 15039842]

(15). Jaki B, Heilmann J, Sticher O. J. Nat. Prod. 2000; 63:1283-1285. [PubMed: 11000038]

(16). Jaki B, Orjala J, Sticher O. J. Nat. Prod. 1999; 62:502-503. [PubMed: 10096870]

(17). Prinsep MR, Thomson RA, West ML, Wylie BL. J. Nat. Prod. 1996; 59:786-788. [PubMed: 8792625]

(18). Whitfield FB, Helidoniotis F, Shaw KJ, Svoronos D. J. Agric. Food Chem. 1999; 47:2367-2373. [PubMed: 10794638]

(19). Graber MA, Gerwick WH, Cheney DP. Tetrahedron Lett. 1996; 37:4635-4638.

(20). Littler, DS.; Littler, MM. South Pacific Reef Plants. Offshore Graphics, Inc.; Washington, D.C.: 2003.

(21). Snell, TW. Small-Scale Freshwater Environment Toxicity Test Methods. Blaise, C.; Ferard, JF., editors. Kluwer; Dordrecht, The Netherlands: 2005.

(22). Lee FYF, Borzilleri R, Fairchild CR, Kim SH, Long BH, Reventos-Suarez C, Vite GD, Rose WC, Kramer RA. Clin. Can. Res. 2001; 7:1429-1437.

(23). Collins LA, Franzblau SG. Antimicrob. Agents Chemother. 1997; 41:1004-1009. [PubMed: 9145860]

(24). Smilkstein M, Sriwilaijaroen N, Kelly JX, Wilairat P, Riscoe M. Antimicrob. Agents Chemother. 2004; 48:1803-1806. [PubMed: 15105138]

(25). Bennett TN, Paguio M, Gligorijevic B, Seudieu C, Kosar AD, Davidson E, Roepe PD. Antimicrob. Agents Chemother. 2004; 48:1807-1810. [PubMed: 15105139]

(26). Trager W, Jensen JB. Science. 1976; 193:673-675. [PubMed: 781840] 

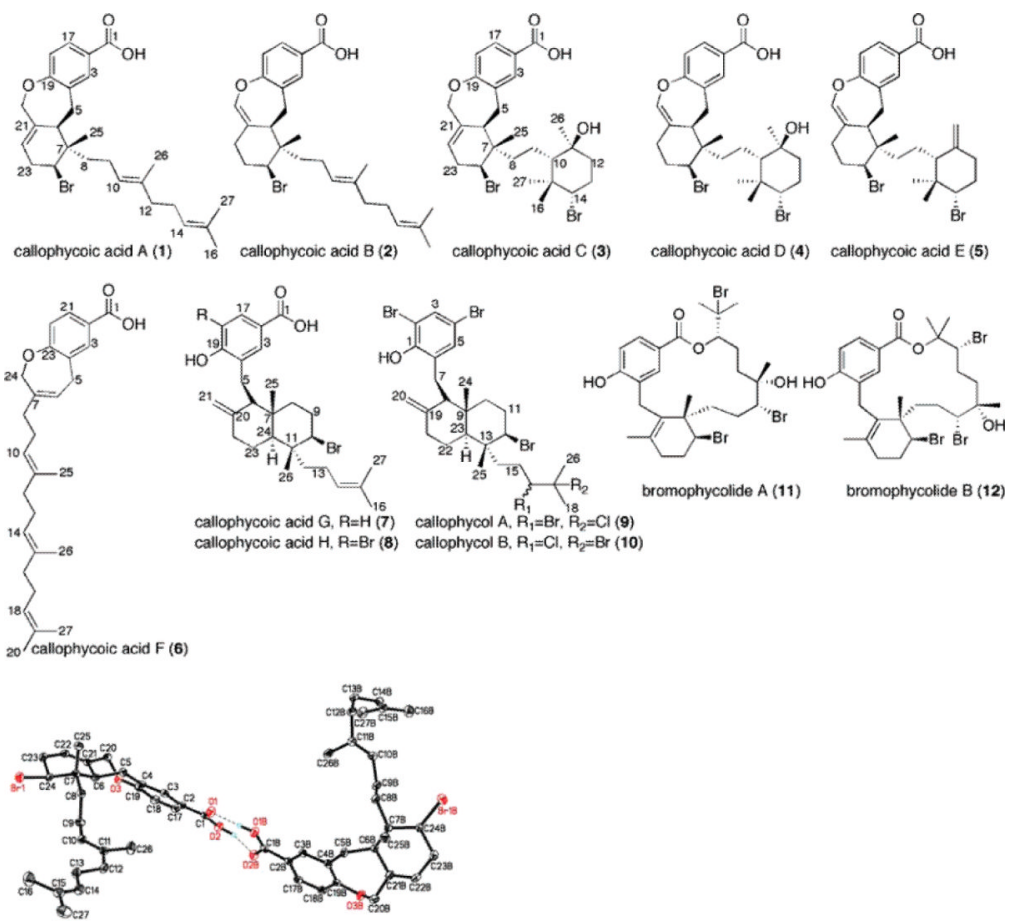

Figure 1.

Perspective drawings of X-ray crystal structures of callophycoic acid A (1). These structures differ only in diterpenoid chain rotation. 

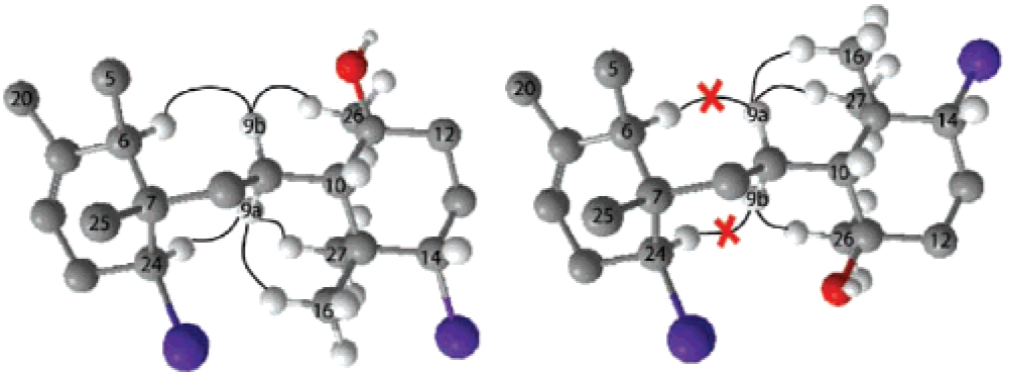

Figure 2.

Proposed partial 3D structure of callophycoic acid C (3) (left) and incorrect configuration (right). Lines in the left drawing indicate selected observed NOEs that support $10 S, 11 S$, $14 S$ absolute stereochemistry. X's denote NOEs not observed. 


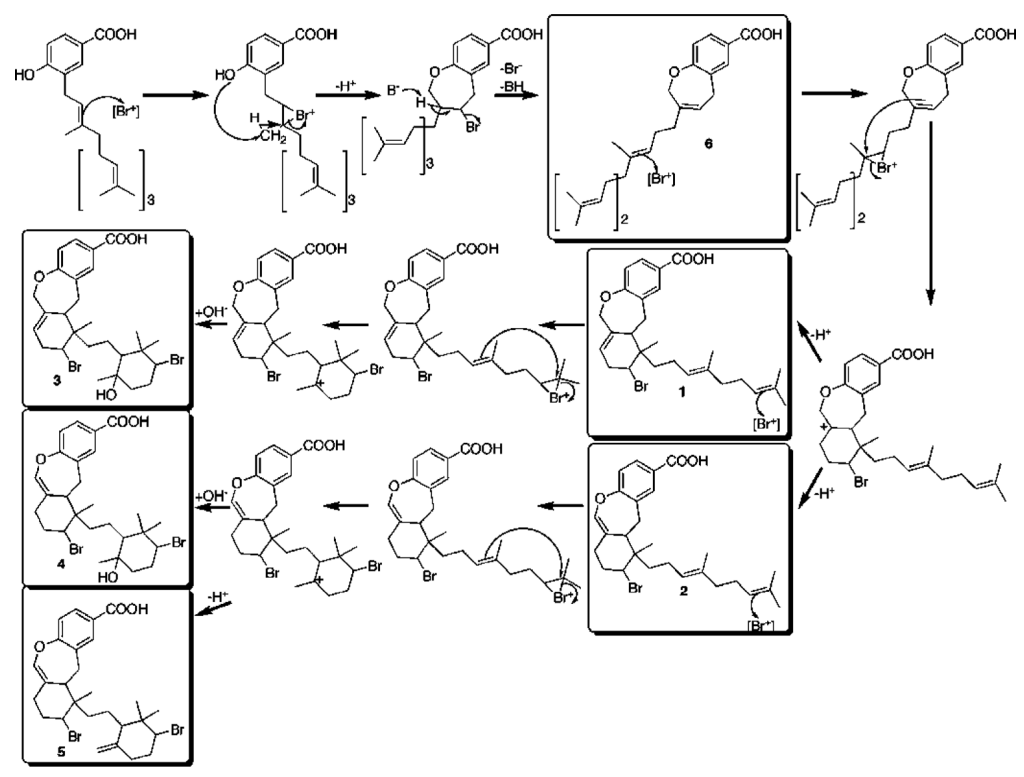

Scheme 1.

Proposed Biosynthesis of Callophycoic Acids A-F (1-6) 

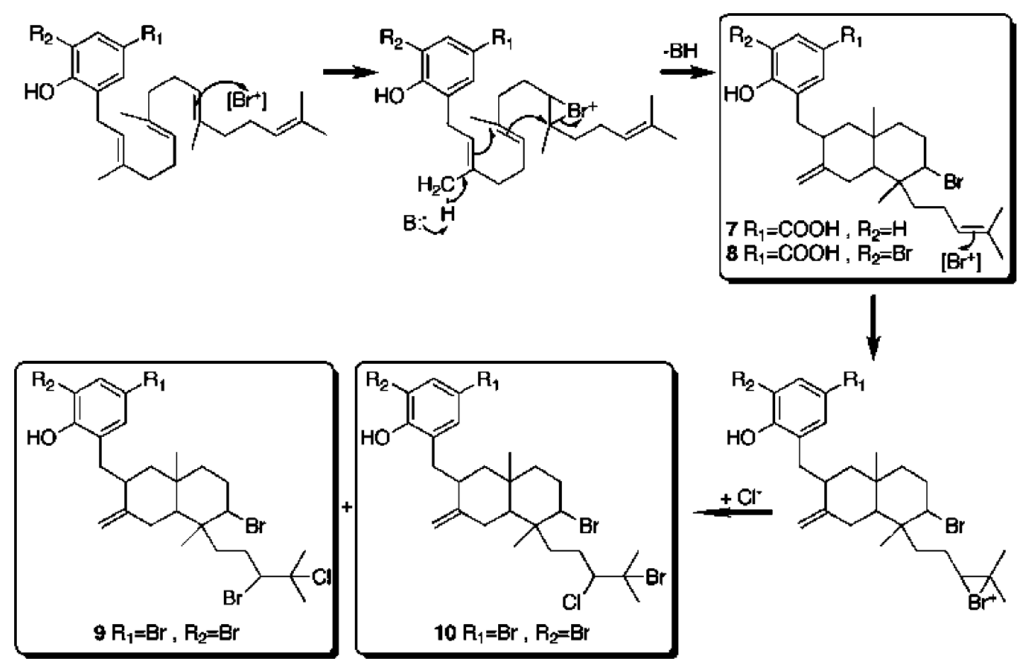

Scheme 2.

Proposed Biosynthesis of Callophycoic Acids G and H (7 and 8) and Callophycols A and B (9 and 10) 


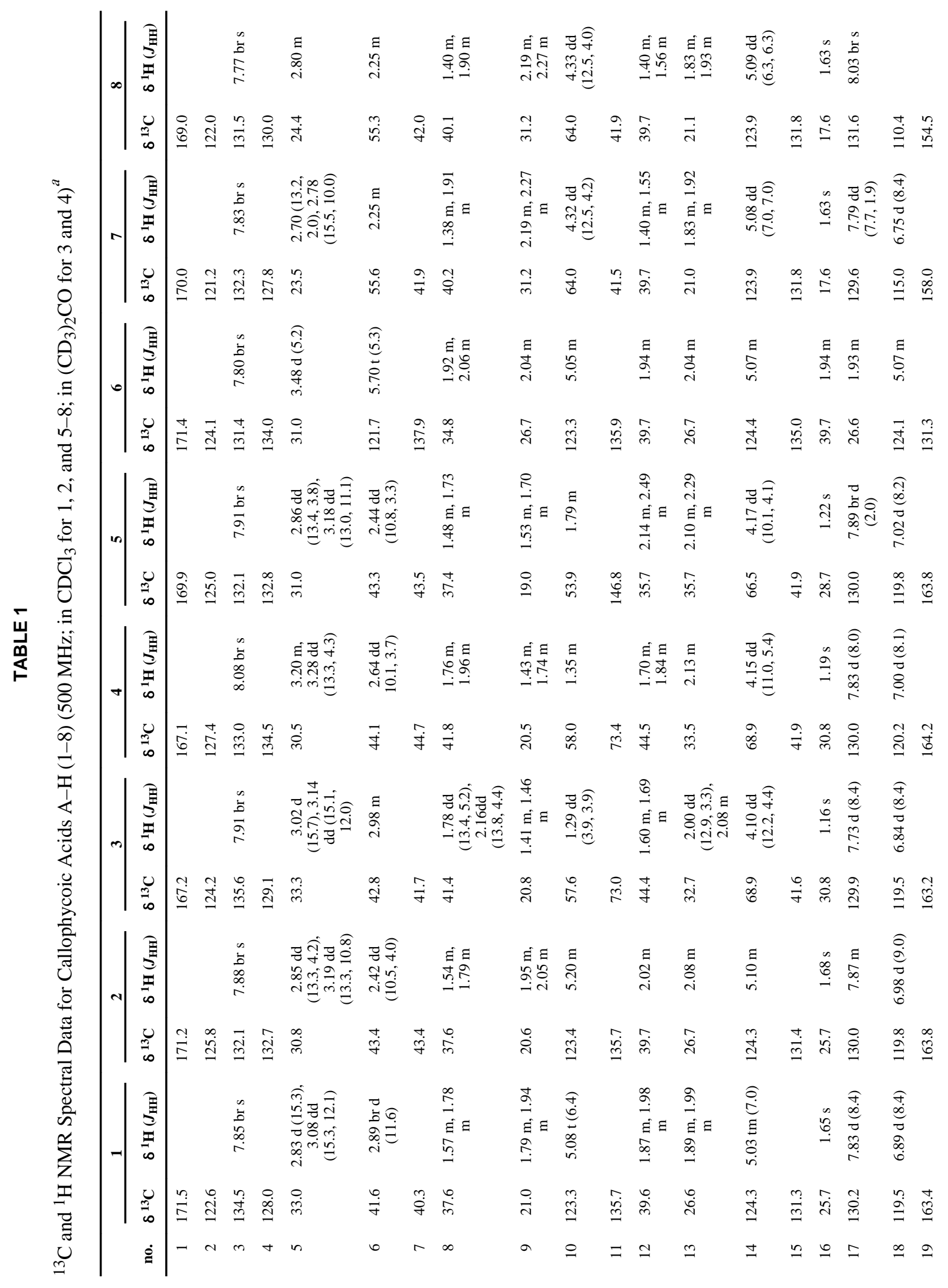




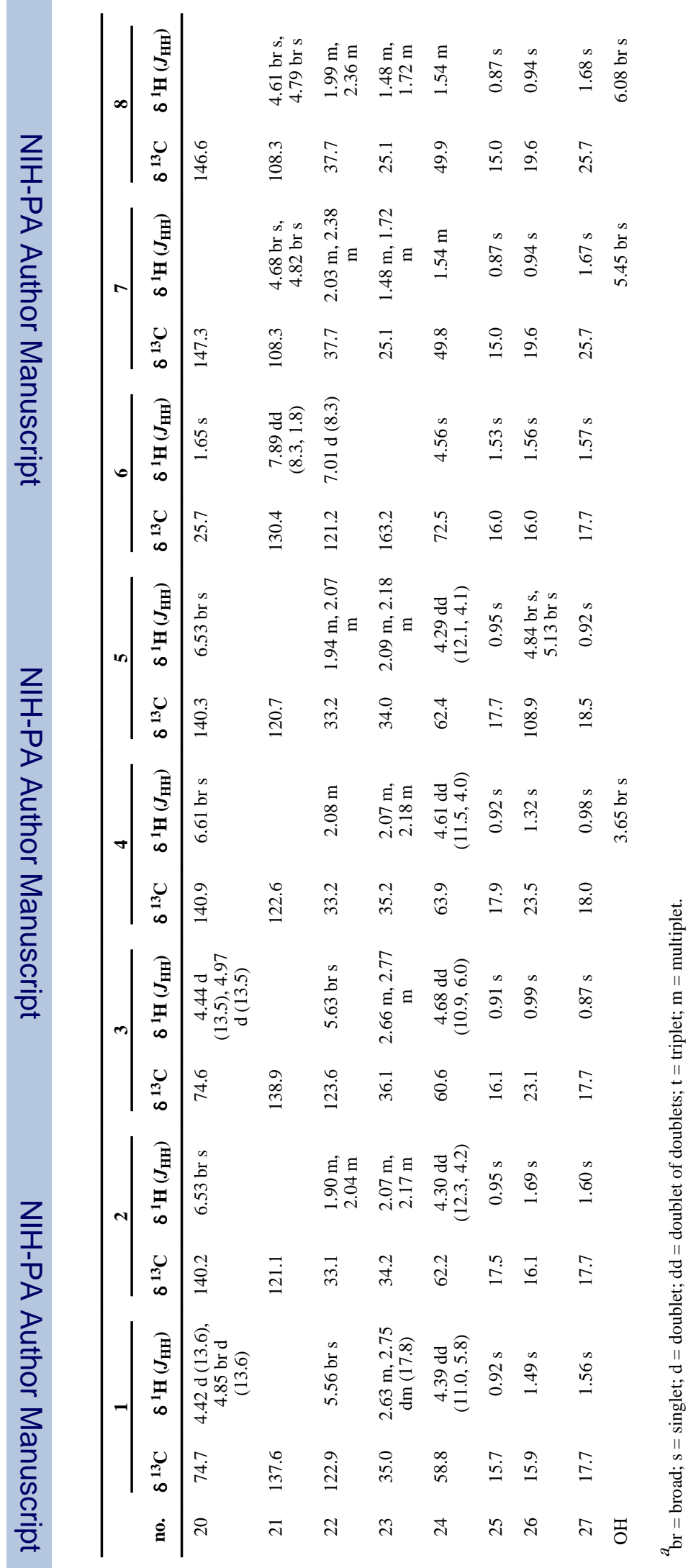


TABLE 2

${ }^{13} \mathrm{C}$ and ${ }^{1} \mathrm{H}$ NMR Spectral Data for Callophycols A and B (9 and 10) $\left(500 \mathrm{MHz} \text {; in } \mathrm{CDCl}_{3}\right)^{\mathrm{a}}$

\begin{tabular}{|c|c|c|c|c|}
\hline \multirow[b]{2}{*}{ no. } & \multicolumn{2}{|r|}{9} & \multicolumn{2}{|r|}{10} \\
\hline & $\delta^{13} \mathrm{C}$ & $\delta^{1} \mathbf{H}$ & $\delta^{13} \mathrm{C}$ & $\delta{ }^{1} \mathbf{H}$ \\
\hline 1 & 149.3 & & 149.3 & \\
\hline 2 & 110.7 & & 110.8 & \\
\hline 3 & 131.1 & $7.39 \mathrm{~d}(2.2)$ & 131.1 & 7.39 br s \\
\hline 4 & 112.2 & & 112.2 & \\
\hline 5 & 132.1 & $7.13 \mathrm{~d}(2.2)$ & 132.1 & $7.13 \mathrm{br} \mathrm{s}$ \\
\hline 6 & 131.3 & & 131.3 & - \\
\hline 7 & 24.5 & $2.73 \mathrm{~d}(2.8), 2.75 \mathrm{br} \mathrm{s}$ & 24.4 & $2.74 \mathrm{br} \mathrm{s}, 2.75 \mathrm{br} \mathrm{s}$ \\
\hline 8 & 55.4 & $2.14 \mathrm{~m}$ & 55.4 & $2.14 \mathrm{~m}$ \\
\hline 9 & 39.9 & & 39.9 & \\
\hline 10 & 40.1 & $1.35 \mathrm{~m}, 1.87 \mathrm{~m}$ & 40.1 & $1.37 \mathrm{~m}, 1.87 \mathrm{~m}$ \\
\hline 11 & 31.2 & $2.18 \mathrm{~m}, 2.24 \mathrm{~m}$ & 31.1 & $2.19 \mathrm{~m}, 2.25 \mathrm{~m}$ \\
\hline 12 & 63.2 & $4.15 \mathrm{dd}(12.4,4.4)$ & 63.8 & $4.21 \mathrm{dm}(10.2)$ \\
\hline 13 & 42.0 & & 42.1 & \\
\hline 14 & 38.8 & $1.38 \mathrm{~m}, 2.06 \mathrm{~m}$ & 38.0 & $1.57 \mathrm{~m}, 1.86 \mathrm{~m}$ \\
\hline 15 & 28.0 & $1.68 \mathrm{~m}, 2.26 \mathrm{~m}$ & 28.2 & $1.50 \mathrm{~m}, 2.33 \mathrm{~m}$ \\
\hline 16 & 65.5 & 3.90 brd (9.8) & 72.7 & $3.91 \mathrm{~d}(10.1)$ \\
\hline 17 & 72.7 & & 68.3 & \\
\hline 18 & 33.5 & $1.79 \mathrm{~s}$ & 33.6 & $1.92 \mathrm{~s}$ \\
\hline 19 & 146.3 & & 146.4 & \\
\hline 20 & 108.8 & $4.60 \mathrm{br} \mathrm{s}, 4.80 \mathrm{br} \mathrm{s}$ & 108.7 & $4.60 \mathrm{br} \mathrm{s}, 4.80 \mathrm{br} \mathrm{s}$ \\
\hline 21 & 37.7 & $1.95 \mathrm{~m}, 2.35 \mathrm{dm}(12.7)$ & 37.8 & $1.96 \mathrm{~m} 2.35 \mathrm{~m}$ \\
\hline 22 & 25.2 & $1.48 \mathrm{~m}, 1.67 \mathrm{~m}$ & 25.0 & $1.47 \mathrm{~m}, 1.75 \mathrm{~m}$ \\
\hline 23 & 50.7 & $1.43 \mathrm{~m}$ & 50.1 & $1.39 \mathrm{~m}$ \\
\hline 24 & 15.1 & $0.86 \mathrm{~s}$ & 15.2 & $0.86 \mathrm{~s}$ \\
\hline 25 & 19.8 & $0.99 \mathrm{~s}$ & 19.7 & $0.99 \mathrm{~s}$ \\
\hline 26 & 26.6 & $1.70 \mathrm{~s}$ & 28.3 & $1.82 \mathrm{~s}$ \\
\hline $\mathrm{OH}$ & & $5.60 \mathrm{br} \mathrm{s}$ & & 5.59 br s \\
\hline
\end{tabular}

$\mathrm{br}=$ broad $\mathrm{s}=$ singlet $\mathrm{d}=$ doublet; $\mathrm{dd}=$ doublet of doublets; $\mathrm{m}=$ multiplet 
